\title{
Contrato y Utopía: ConTINUIDAD y Discontinuidad de Los Mitos Libertarios de ANarquía, Estado y UTopía ${ }^{I}$
}

\author{
Felipe Schwember Augier ${ }^{2}$
}

\begin{abstract}
RESUMEN: El presente trabajo examina Anarquía, Estado y utopia de Robert Nozick a la luz de los mitos y ficciones sobre los cuales se construye. En este sentido, se sostendrá que es posible identificar dos mitos principales: el estado de naturaleza lockeano, cuyo principio se deja resumir en la máxima volenti non fit iniuria; y la meta-utopía libertaria, que se deja explicar como una aplicación de la teoría evolutiva de Hayek y de la epistemología de Popper a la construcción de una utopía. Se sostendrá además que existe una continuidad entre ambos mitos y que dicha continuidad viene dada por una intuición moral que Nozick formula al principio de la obra y que sirve también de inspiración al mito libertario: que la vida solo puede tener sentido cuando se deja a cada persona vivir la suya del modo en que estime conveniente. Dicha intuición, se concluirá, se traduce en el campo de la política y del derecho en el principio de que cada persona es dueńa de sí misma y que, por consiguiente, esta forma particular de propiedad constituye el secreto hilo conductor de toda la obra.
\end{abstract}

PALABRAS CLAVE: Locke. Contractualismo. Nozick. Ley natural. Utopía.

\section{INTRODUCCIÓN}

La filosofía política neo-contractualista — bajo la que se suela agrupar a Rawls, Nozick, Buchanan, Gauthier, entre otros — ha reflotado uno de los mitos perennes de la filosofía política: el contrato social, esto es, la narración que describe el origen ideal de los vínculos normativos a partir de una convención originaria. "Mito" aquí no tiene un sentido peyorativo; por el contrario, el "mito contractualista" hace referencia a un ejercicio de (auto)esclarecimiento intelectual realizado al hilo de (o con el auxilio de) una imagen que captura la intuición moral fundamental que se deja expresar en el principio volenti non fit iniuria, "al que consiente no se le hace daño". La imagen en cuestión es la

\footnotetext{
${ }^{1}$ El presente trabajo es parte del proyecto Fondecyt regular (Chile) № 1160982 titulado "Crítica y recepción de las utopías y del utopismo en el liberalismo libertario y en el liberalismo socialdemócrata del siglo XX: Popper, Hayek, Nozick y Rawls."

http://dx.doi.org/10.1590/S0101-31732016000400007

${ }^{2}$ Profesor del Centro de Investigación en Teoría Social y Política de la Escuela de Gobierno, Universidad Adolfo Ibánez. Correo electrónico felipe.schwember@uai.cl
} 
que se dibuja a partir de la descripción de una hipotética situación inicial, el estado de naturaleza, que contiene ciertas condiciones que delimitan un marco para la negociación o discusión colectiva de los principios generales de la vida social. Esta negociación o discusión (igualmente hipotética) desembocará en un contrato fundacional, el contrato social, que reflejará esas condiciones ideales y, con ello, los principios de la justicia.

El hecho de que el neo-contractualismo apele de modo sistemático a un mito para dilucidar y articular ciertos principios de filosofía política no debiera resultar ni extraordinario ni embarazoso. La filosofía se ha servido siempre profusamente de la imaginación: el mito del anillo de Giges, la alegoría de la caverna, el mito de la Atlántida, la narración de Aristófanes en el Banquete - por mencionar solo alguno de los mitos más famosos de Platónel genio maligno de Descartes, el esquematismo trascendental kantiano y la epoché fenomenológica son, en distinta medida, ejemplos de ello. Pero como en el caso de la filosofía política, como afirmara certeramente Frye (1982, p. 55), dos son las concepciones sociales que únicamente pueden expresarse en términos de mito, el contrato social y la utopía, a los mitos platónicos recién señalados habría que añadir aún los mitos de la Utopia de Tomás Moro, la Nueva Atlántida de Bacon, La ciudad del sol de Campanella, y un largo etcétera, que remite a toda la larga tradición de la literatura utópica ${ }^{3}$. Ambos mitos constituyen la imaginería que sirve de medio al razonamiento del filósofo político, y que pueden ser considerados como complementarios en la medida en que el primero, el mito contractualista, busca relatar la génesis ideal de la sociedad y de las normas que le sirven de sostén, mientras que el segundo, el mito utópico, busca describir un futuro político ideal. De este modo - y simplificando bastante - podría afirmarse que la diferencia entre uno y otro puede indicarse sumariamente afirmando que el mito contractualista parte de la pregunta “¿cómo debería haber sido la génesis de la sociedad (su estructura social, política y eventualmente económica, así como el conjunto de normas jurídicas que son expresión de todo aquello) para que ésta hubiera podido ser considerada como justa?” mientras que las narraciones utópicas se orientan no al pasado y a la génesis ideal de las normas, sino a su realización futura, y que por eso su tarea se deja expresar en la siguiente pregunta: "cómo tendría que

\footnotetext{
${ }^{3} \mathrm{Si}$ además se consideran ciertas ideas que prevalecieron en su día y se colaron en la filosofía política, podemos añadir a la lista de "mitos" (en el sentido ahora de "pseudo-ciencia") la idea del progreso indefinido y toda la filosofía de la historia que, inspirada en ella, pretendió exactitud científica. Es interesante notar, además, que dichos mitos eclipsaron o incluso sustituyeron al contractualismo por todo el tiempo que va desde, digamos, Kant y Fichte hasta Rawls.
} 
llegar a ser la sociedad y las instituciones que la constituyen para que pudiera ser considerada como justas?”.

Anarquía, Estado y utopía de Robert Nozick ${ }^{4}$ es un libro que tiene la particularidad de estar plagado de mitos y de experimentos mentales de distinto tipo: el estado de naturaleza lockeano, la máquina de experiencias, explicaciones hipotéticas de mano invisible, demóktesis y la descripción de la meta-utopía libertaria. Esta profusión de mitos y de experimentos lo convierten no solo en un libro ejemplar para acometer un estudio de las herramientas y artificios metódicos que se emplean en filosofía, sino que además lo convierten en uno de los pocos — cuando no en el único- libro de filosofía política que ofrece al mismo tiempo, y como dos líneas de argumentación independientes, un mito contractualista y un mito utópico.

En el presente trabajo se examinarán los presupuestos e intuiciones generales de ambos mitos con el fin de comprobar la continuidad y compatibilidad general que existe entre ellos. El primero, presentado en las primeras dos partes del libro, como se sabe, se forja y desarrolla a partir del mito del estado de naturaleza lockeano. El segundo, en cambio, no reivindica ningún mito ni ninguna tradición particular pero, como se espera poner de manifiesto, se deja explicar como el intento de elaborar una utopía a partir de la aplicación de la teoría evolutiva de las instituciones de Hayek y de la epistemología de Popper. Como se espera demostrar, ambos mitos, el del estado de naturaleza lockeano y la (meta)utopía libertaria, no solo son compatibles sino también complementarios en la medida en que se desarrollan a partir del mismo principio, propiamente nozickiano, de que cada uno puede disponer de sí con total libertad y sin restricción alguna, del principio de que, en definitiva, cada uno es dueño de sí mismo (self-ownership).

\section{El ESTADO DE NATURALEZA LOCKEANO: CONTRATOS, PROPIEDAD Y ÓRDENES EMERGENTES}

Uno de los artificios teóricos a que ha recurrido constantemente la filosofía política es el del estado de naturaleza y el contrato social. Dicho artificio, como se sabe, consiste en una narración que describe la génesis ideal de las instituciones políticas. Dicha narración contiene y describe las

\footnotetext{
${ }^{4} \mathrm{Abreviada}$ en lo sucesivo por sus iniciales en inglés, $A S U$. Las obras de autores clásicos como Aristóteles o Kant se las cita del modo canónico. Las citas de $A S U$ están tomadas de la edición castellana, que se adopta con algunas correcciones.
} 
condiciones que, ex hypothesi, son necesarias (y suficientes) para que el poder civil pueda ser tenido, tanto en su génesis como en su ejercicio, como legítimo. La idea fundamental que subyace a este artificio es la intuición moral de que el poder que una persona ejerce sobre otra es legítimo si y solo si la segunda consiente en dicho ejercicio. De este modo, las teorías contractualistas - que son las que se valen de este artificio- procuran rastrear las condiciones ideales en las que ese consentimiento podría ser dado. Si, haciendo una clasificación gruesa, se toman las diferentes versiones de las teorías contractualistas y se las explica a partir del modo en que cada una de ellas ha interpretado y aplicado el principio moral sobre el que descansan, el principio que reza volenti non fit iniuria (al que consiente no se le hace daño), tenemos entonces que las teorías contractualistas de filiación hobbesiana entienden que es racional aquello que maximiza mi propio interés y que, por consiguiente, debo hacer aquello que prescribe la norma solo si ésta efectivamente contribuye a dicha maximización; las teorías que pueden adscribirse a la tradición rousseauniana-kantiana entienden que el principio volenti non fit inuiria implica que el ejercicio del poder, las normas (y eventualmente las instituciones) son legítimas/justas cuando hubieran podido ser consistentemente aprobadas por todos. En este sentido, es justo aquel que quiere y obra conforme la voluntad general, esto es, aquel cuyo interés coincide (o podría coincidir) con el de todos los demás sin contradicción. La tradición que se inspira en Locke, en cambio, es menos exigente por lo que a dicha coincidencia se refiere. Mientras que en el caso del contractualismo de inspiración rousseauniana debe haber una identidad entre los intereses particulares y los intereses generales, en el caso del contractualismo de inspiración lockeana no existe propiamente un interés general, de modo que basta con que los diferentes intereses particulares no colisionen. Por consiguiente, en un universo lockeano cada uno puede buscar legítimamente su propio interés mientras no dañe con ello a terceros. Por este motivo, esta clase de contractualismo entiende que las normas, así como las instituciones y, en general, las relaciones entre individuos son justas si son fruto de un acuerdo libre y voluntario, esto es, si han sido acordadas sin que en ello haya sido determinante la fuerza o el engaño. Basta con eso. Asimismo, esta última condición (i.e., la ausencia de violencia o fraude) es esencial, pues es ella, en definitiva, la que permite trazar la línea divisoria entre el lockeanismo y el hobbesianismo (no se debe olvidar la sentencia de Hobbes de que los pactos celebrados por miedo son voluntarios). En ambos casos se admite que los individuos obran movidos por la consecución de sus propios intereses, pero en el caso de Locke esa consecución no puede tener lugar, ni aun en 
estado de naturaleza, en perjuicio o a costa de otros. Esa limitación, que es expresión de la ley natural y de los derechos naturales que le son correlativos, es reflejo, a su vez, del hecho de considerar el respeto del arbitrio individual como el principio fundamental del derecho y de la política. Este principio de la justicia/legitimidad de las acciones es recogido por Nozick (1988, p. 65) en su idea de los derechos individuales naturales: "Una línea (o un hiperplano) circunscribe un área de espacio moral alrededor de un individuo".

El resultado de todo lo anterior es que, como diría Gauthier, el estado de naturaleza no puede ser concebido como un estado de depredación, sino como estado de cooperación mutua. Esto no significa considerar el estado de naturaleza como una suerte de estado de inocencia, un Edén en el que no existen los conflictos; además, en cierto sentido el que lo sea o no es irrelevante. La idea, más bien, es que los conflictos, y más precisamente, el uso de la fuerza y el fraude no son, por definición, criterios suficientes para determinar qué es justo y qué no. Si suponemos que dicho criterio viene dado por el principio volenti non fit iniuria y que dicho principio significa, básicamente, dejar a los individuos obrar según su propia elección sin otra restricción que la de permitir con ello a otros obrar de ese mismo modo, entonces tenemos las bases de la filosofía política y jurídica de Locke. De todo lo anterior se siguen, a modo de corolario, dos principios básicos: a) libertad para adquirir propiedades y b) libertad de contratación. Ciertamente, la justificación de la propiedad es más complicada, pues no se sigue de una manera lineal del principio volenti non fit iniuria, por lo que volveremos en seguida sobre ella. Por el momento baste simplemente dejar establecido que ambos principios son, a fin de cuentas, una consecuencia del hecho de que cada individuo sea naturalmente libre y de que su libertad deba ser respetada por otros. Una vez establecido estos dos principios, lo demás viene por ańadidura; y es aquí donde el mito empieza a cobrar su forma, pues el mercado aparece ahora sin más como un epifenómeno de la aplicación regular de los mentados principios sin que para ello sea menester la intervención de autoridad central alguna. Y, más aún, el mito hace tendencialmente superflua la instauración de una autoridad tal, pues viene a decir que, al menos ex hypothesi, hay un escenario donde no sólo las necesidades personales pueden ser totalmente satisfechas por medio de los intercambios y de la cooperación voluntaria, sino que las demandas de justicia también pueden serlo aunque no exista una autoridad jurisdiccional central.

Ciertamente, para que esta conclusión sea posible es necesario que el ejercicio de la administración de justicia pueda funcionar íntegramente 
sobre la base de arbitrajes y contratos privados sin que ello derive en algún momento en una seguidilla de vendettas o en un servicio de imposición de represalias en contra de los que, real o imaginariamente, han vulnerado los derechos de otro(s). Locke defiende el ejercicio de la justicia privada en estado de naturaleza y aduce en su favor fundamentalmente dos razones: a) sin un derecho tal — que podríamos denominar meta-derecho- nuestros otros derechos naturales carecerían de toda eficacia (si yo tengo un derecho debo también tener el derecho a poder exigirlo, llegado el caso) (LOCKE, 1988, II $\$ 7,6-12)$.; b) el derecho del magistrado para infligir castigo a los particulares no puede provenir sino del derecho natural a ejecutar la ley natural; la fuente de su autoridad no puede ser, al fin y al cabo, otra que la que en principio tenemos unos sobre otros para ejecutar dicha ley (LOCKE, 1988, II \$9).

Es cierto que Locke dice que esta doctrina que defiende el ejercicio privado de la justicia (lo que podríamos llamar un "derecho natural a castigar") es algo peculiar y que, además, el ejercicio de un derecho tal produciría múltiples inconvenientes, inconvenientes que es mejor evitar delegando el ejercicio del mismo en un tercero imparcial (el magistrado). No obstante, es innegable también que toda esta concepción delineada en sus líneas principales por Locke abre la posibilidad de disolver progresivamente la política en una suma acuerdos particulares haciendo con ello el contrato social superfluo e imposible, al mismo tiempo. "Superfluo", porque, como se ha adelantado ya, los acuerdos particulares podrían ser suficientes para regular íntegramente la vida de los individuos y servir a todas sus necesidades; e "imposible" porque, si se toma en serio la necesidad de que los individuos presten de modo real y efectivo su consentimiento, la celebración de un contrato como el contrato social, que por definición requiere unanimidad, no tendrá ni podrá tener nunca lugar. Por esto no es de extrañar que entre los epígonos de Locke, la narración ideal que rastrea las condiciones de las relaciones justas entre los individuos tienda a agotarse en la descripción del estado de naturaleza y, con ello, a inclinarse hacia el anarquismo, entendido ahora como la privatización total de la propia vida: cada uno vive como quiere y trata con quienes quiere, en total libertad y sin emplear la fuerza más que para defenderse; así, más que un contrato social tenemos múltiples, infinitos contratos particulares que dan origen a múltiples comunidades, permanentes o no, que reflejan a su vez las variopintas diferencias de aquellos que las componen. 


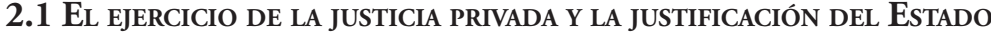

Con todo, uno podría preguntarse por qué no se supone la intención de los individuos de constituir una autoridad jurisdiccional y policial común. Después de todo, la narración descansa sobre fuertes suposiciones e idealizaciones, especialmente en que la disposición de los individuos a cooperar recíprocamente de buena fe haría posible un mercado; que en consecuencia la violencia y el fraude no alcanzarían nunca el nivel crítico que hiciera imposible dicha cooperación. Sin embargo, la lógica interna del mito libertario admite todas estas suposiciones — la exigen, de hecho - pero no es compatible con la suposición de instaurar una autoridad jurisdiccional. En la estela de Locke, el libertarismo sólo admite el consentimiento real (ya sea expreso o tácito) y nunca el consentimiento hipotético por una razón muy sencilla: nadie puede ser obligado jurídicamente por una medio de una ficción y en base a suposiciones. El mercado, por consiguiente - esta es la idea - podría surgir si otros comenzaran a intercambiar regularmente bienes y servicios aun cuando yo me abstuviera de participar en dichos intercambios. El Estado, en cambio, no puede surgir de ese modo porque a diferencia de los intercambios que realizan terceros, los mandatos y prohibiciones del Estado se aplican a todos los individuos de un determinado territorio sin excepción. En consecuencia, la instauración de una autoridad central requiere del acuerdo unánime de los individuos. Esta improbable exigencia explica la deriva anarquista del mito del estado de naturaleza lockeano conocida con el nombre de "anarco-capitalismo".

En un intento por evitar dicha deriva anarquista, Nozick elabora una historia que pretende demostrar la posibilidad —y tan solo la posibilidaddel surgimiento legítimo — en los términos del mito lockeano- del Estado sin que ello suponga el acuerdo unánime de los individuos que quedan sometidos a su autoridad. Para ello Nozick echa mano de una herramienta metódica muy socorrida en la tradición liberal: una explicación de mano invisible. Dicha herramienta pretende ofrecer una explicación potencial fundamental del campo político esto es, una explicación que permita dar cuenta de la política - es decir, de la existencia de un Estado que detenta el monopolio de la fuerza - en términos no políticos. Dicho de otro modo, Nozick intenta elaborar una narración hipotética en la que el Estado sea el resultado emergente e inintencionado de la suma de ciertas acciones particulares. Dicha narración discurre aproximadamente así: los individuos en estado de naturaleza lockeano respetan por regla general los derechos ajenos; pero como de todos 
modos hay transgresores, forman asociaciones de protección para auxiliarse mutuamente. Como dichas asociaciones son ineficientes, se forman agencias de protección que ofrecen servicios profesionales de defensa y reivindicación. Como el relato debe respetar los supuestos del estado de naturaleza lockeano, se da por descontado que dichas agencias, además de servir a sus clientes honestamente (no les defraudan ni abusan; tampoco les avalan cuando son culpables de alguna transgresión), compiten de forma leal entre sí (no hay guerras ni sabotajes entre ellas, o no al menos de modo general) (NOZICK, 1988, p. 30). A medida que pasa el tiempo — prosigue el relato de Nozick —, y en virtud de los procesos normales de competencia de mercado, se crean y desaparecen algunas agencias mientras otras perduran y se consolidan como las principales en un territorio. Como, por otra parte, estas agencias dominantes no pueden obligar a los individuos de su territorio a contratar sus servicios ni pueden tampoco impedirles que protejan y reivindiquen por sí mismos sus propios derechos, "[...] el territorio cubierto por la asociación de protección semejaría, entonces, una rebanada de queso suizo, con linderos internos y externos." (NOZICK, 1988, p. 63).

En este punto de la narración tenemos un Estado ultramínimo, representado por la agencia de protección dominante, que es el resultado inintencionado de la competencia entre las diferentes agencias de protección. Este Estado ultramínimo es entonces producto de un sinnúmero de contratos individuales de protección y, por lo mismo, no protege ni reivindica los derechos de los independientes, es decir, de aquellos que han desistido de contratar sus servicios de protección. Evidentemente, puede que el independiente tenga alguna vez alguna controversia con alguno de los clientes de la agencia, de modo que se produzca una suerte de contienda de jurisdicciones al momento de juzgar el caso. El independiente puede insistir en aplicar su procedimiento particular para juzgar y eventualmente castigar y/o exigir compensación al cliente de la agencia. La agencia, por su parte, puede hacer lo mismo de modo que la narración llega a un nudo insoluble pues ninguno de los dos tiene mejor derecho para aplicar su procedimiento con preferencia al del otro. A eso hay que sumarle otra complicación, a saber, que no existe un meta-procedimiento que permita resolver estos conflictos jurisdiccionales o, en términos más sustantivos, para determinar qué procedimiento es mejor. Uno podría desestimar, ciertamente, muchos procedimientos por considerar que atentan contra los derechos individuales o porque son irracionales. Por ejemplo, aquellos en que no se admite la bilateralidad de la audiencia, se admiten las ordalías o, por citar al mismo Nozick, pretenden determinar la culpabilidad 
del acusado mediante la lectura de las hojas de té. No obstante, fuera de estos casos más bien grotescos, las diferencias entre las reglas procedimentales que pueden ser legítimamente muy amplias — son irresolubles.

Nozick resuelve este nudo al que llega su narración de un modo que resulta dudoso en los términos del marco lockeano que adopta. Afirma que la agencia podría anunciar que se reservará el derecho de juzgar los procedimientos de administración de justicia que se vaya a aplicar a sus clientes y que, en concreto, no permitirá aquellos procedimientos que considere riesgosos. Esta prohibición de la agencia lesiona el derecho de los independientes a hacerse justicia por su propia mano y por eso Nozick hace entrar en juego otro principio - que parece ser más bien un principio ad hoc- el principio de compensación. En virtud del mismo se entiende que un individuo tiene derecho a prohibir a otro una acción riesgosa a cambio de una compensación. De este modo, la agencia tendría derecho a prohibir al independiente el ejercicio de su derecho a castigar a sus clientes a cambio de una compensación. La compensación será el ofrecimiento de cobertura gratuita.

La introducción de este principio suscita al menos tres problemas. El primero es si este principio es compatible o no con el trasfondo lockeano en el que se desarrolla la narración; otro, vinculado directamente con el primero y subrayado por Mack $(1982,2011)$, es el cambio que supone para la concepción nozickiana de los derechos; el tercero es si acaso el independiente podría él ejercer este derecho contra la agencia.

Con respeto al primero, es preciso no perder de vista que podría entenderse la estipulación de Locke y la teoría lockeana de la propiedad en su conjunto como el desarrollo de un razonamiento igual o muy parecido al ofrecido por Nozick en relación al problema del castigo: puesto que en un principio las cosas son res communes, su apropiación particular entraña, prima facie, la vulneración de los derechos de los comuneros. Esa vulneración, con todo, no tiene lugar si compenso suficientemente a los demás por ella. Es tentador suponer que Locke propuso el trabajo como el modo originario de adquirir no sólo porque ofrece menos problemas que la occupatio en lo tocante a la determinación de los límites de una apropiación sino porque, además, al aumentar el valor de las cosas, ofrece con ello una compensación (indirecta) a todos los demás. Locke se detiene en este problema particularmente en el caso de la apropiación de la tierra, pues ésta no puede multiplicarse o aumentarse físicamente mediante el trabajo. No obstante, puede aumentarse su valor (o utilidad) mediante el trabajo. De ahí que Locke (II\$ 37, 13) afirme cosas 
como que aquel que se apropia de una cantidad de tierra no disminuye sino que "[...] aumenta el abasto común de la humanidad" o que aquel que cerca un acre de tierra, con su trabajo, "ha regalado noventa acres a la humanidad" (LOCKE, II\$ 37, 19-20) o, en fin, que un jornalero en Inglaterra vive mejor que un rey en América (donde la propiedad de la tierra es común; LOCK, II \$41). Aunque la compensación es indirecta (el adquirente no debe dar parte de su trabajo a otros; basta con que aumente las existencias disponibles para esos otros), alcanza para justificar las apropiaciones privadas pues deja (o debiera dejar) a esos otros en — como diría Nozick - el mismo punto en la curva de indiferencia. Pues bien, si esta es una interpretación plausible de la teoría de la apropiación de Locke, entonces el principio de compensación que Nozick introduce para justificar el Estado mínimo es concordante con el mito del estado de naturaleza lockeano en la medida en que sigue la misma lógica que el principio de justa adquisición de Locke.

Suponiendo entonces que el principio de compensación no es una herejía nozickiana del lockeanismo, ¿̨uál es entonces la concepción de los derechos que subyace a $A S U$ ? Mack tiene seguramente razón al afirmar que con la introducción de este principio se debe entender que los derechos libertarios de Nozick consisten no en prohibiciones absolutas de actuar (de traspasar el hiperplano), sino en prohibiciones sujetas a la necesidad de compensar en caso de que ciertos límites sean traspasados (MACK, 2011, p. 108-109). Con todo, el tratamiento que hace Nozick de esta cuestión, así como los problemas que plantea la observación de Mack, suscitan muchas más aristas y dificultades que las que se pueden abordar ahora aquí. Al respecto baste insistir, por las razones recién apuntadas a propósito del principio de compensación y la teoría de la adquisición de Locke, en la posibilidad de ofrecer una interpretación compatibilista entre dicha concepción de los derechos y el marco lockeano en el que se desarrolla $A S U$.

Pareciera, por último, que cuando Nozick afirma que la agencia está en condiciones de impedir los procedimientos y reivindicaciones temerarias del independiente, pero no al revés, está apelando a un argumento realista (del tipo "lo hace porque puede y punto"). Pero evidentemente un razonamiento tal es incompatible con el marco lockeano de la historia y en consecuencia debe entenderse que Nozick quiere decir que solo la agencia puede bloquear al independiente y no el independiente a la agencia no porque la agencia sea más fuerte sino simplemente porque ella sí puede compensar al independiente por la prohibición mientras que el independiente no está en condiciones de hacer lo propio con todos los clientes de la agencia. 
Los adversarios anarco-capitalistas de Nozick han celebrado mucho las dificultades a que da lugar la narración de Nozick sin caer en cuenta de que éstas pueden significarles tan solo una victoria pírrica. Si la prohibición impuesta al independiente a cambio de una compensación es, entre otras cosas, contraria a la ley natural lockeana porque no existe un procedimiento para dirimir los conflictos jurisdiccionales entre el independiente y la agencia; y si tampoco es obligatorio desde un punto de vista político y moral acordar un procedimiento tal, entonces lo que revelan las dificultades en que desemboca la narración de Nozick es que un derecho natural lockeano a defenderse, castigar y reivindicar los propios derechos (en suma, un derecho natural a la justicia privada) conduce a una aporía que para el mito del estado de naturaleza lockeano puede resultar fatal.

\subsection{LA PROPIEDAD Y TRANSFERENCIAS}

Junto con la integridad y libertad individual, la libertad contractual y el derecho a castigar, la propiedad constituye uno de los momentos fundamentales del estado de naturaleza lockeano. La posición de Nozick a este respecto se deja resumir brevemente del siguiente modo: en un principio las cosas carecen de dueño y todos tiene una igual libertad para apropiárselas mediante el trabajo. En consecuencia, cualquiera que trabaje una res nullius se hace dueño de ella siempre y cuando con su apropiación no empeore la situación de otros. "Empeorar" aquí debe entenderse en un sentido débil, esto es, no como el mandato de no disminuir las posibilidades de apropiación de cosas del mismo género, pues eso es inevitable, sino tan solo como el mandato de no suprimir las posibilidades de usar (sin apropiarse) otras cosas del mismo género de que me apropio yo (NOZICK, 1988, p. 177-179). Esta condición de no empeoramiento de la situación de otros es una interpretación de las estipulaciones de Locke, y Nozick la exige no sólo para la adquisición original sino para cualquier adquisición en general. Por consiguiente, las adquisiciones ulteriores que tengan lugar en virtud de intercambios de cualquier tipo, también se ven sujetas a la estipulación. De esta guisa, si hubiese que enunciar los principios de justa adquisición podría hacérselo diciendo que:

1. Una adquisición originaria es justa cuando recae sobre una res nullius y su apropiación no empeora la situación de otro por la vía de suprimir sus posibilidades de usar otras cosas del mismo género de la que me apropio yo. 
2. Una adquisición derivada es justa cuando es el resultado de un acuerdo voluntario en el que el tradente es dueño de la cosa que transfiere y la transferencia no empeora la situación de otro por la vía de suprimir sus posibilidades de usar otras cosas del mismo género de la que me apropio yo 5 .

La inclusión de la estipulación tiene por finalidad, evidentemente, resolver el problema de aquellos que se encuentran en estado de necesidad sin culpa de su parte. La necesidad en el estado de naturaleza lockeano, tal como Nozick la interpreta, deriva, no de un deber jurídico de auxiliar positivamente a otros (pues en dicho estado tales deberes son siempre resultado de la celebración de un acuerdo), sino del deber de no impedir ni obstaculizar la igual libertad que todos naturalmente tienen para usar bienes con vistas a su conservación o a la consecución de cualquier otro fin lícito ${ }^{6}$. De este modo, el dueño de la única fuente en el desierto no puede negar lícitamente el agua a los que la necesitan mientras éstos no encuentren otro lugar donde beber; el dueño de una playa no puede impedir al náufrago que nade hasta sus costas, aun cuando, por otra parte, dichas costas sigan siendo suyas, y así sucesivamente.

Puesto que estos principios pueden ser violados, se requerirá aún de otro principio, el principio de rectificación, que corrija la distribución de las posesiones ordenando devolver a sus legítimos dueńos las cosas que les han sido injustamente arrebatadas, ya sea por la violencia, ya sea por el fraude.

A estos tres principios debe añadirse aún otro que permita recoger a cabalidad la máxima volenti non fit iniuria. Este principio dirá que:

3. Ninguna adquisición es justa sino en virtud de la aplicación de los principios anteriores.

Es importante advertir que con este principio Nozick cierra su teoría de la propiedad para que refleje de modo cabal el principio volenti non fit iniuria. La idea, por tanto, que se sigue de ese principio es que las

\footnotetext{
${ }^{5}$ Se añade en la enunciación "otras cosas del mismo género", pues el que invoca la estipulación solo la puede invocar cuando, en virtud de mi apropiación, no quedan otras cosas del mismo género que él pueda usar; si aún quedan entonces la adquisición que impugna no ha empeorado verdaderamente su situación.

${ }^{6}$ Como se desprende de lo que Nozick (1988, p. 179 nota al pie) dice a propósito de la concepción de Ayn Rand del derecho de propiedad.
} 
adquisiciones y las transferencias de bienes son justas si y solo si son realizadas libre y voluntariamente?

Con todo, esta estricta clausura suscita algunos problemas a la hora de pensar en la aplicación de la teoría. Si la voluntariedad es la medida de la justicia de los contratos, entonces se podría concluir que todos aquellos contratos celebrados bajo la presión de alguna necesidad considerable - pero no tal que haga entrar en juego la estipulación de Locke - son injustos o lo son al menos bajo ciertos respectos ${ }^{8}$. Supongamos, por ejemplo, que a alguien le urge vender lo más pronto posible su casa para pagar un costosísimo y urgente tratamiento médico; y supongamos además que yo, sabedor de su apuro, le ofrezco un precio muy inferior al que él o cualquier otro aceptaría en condiciones normales. El vendedor acepta con resignación. Al obrar de esa manera ¿he cometido injusticia?

Si juzgamos el principio volenti non fit iniuria a la luz de ejemplos como este ¿̇debemos decir que es cierto como regla general, en abstracto, pero eventualmente falso hic et nunc? ¿O por el contrario debemos decir que es sin más verdadero y que casos como los del ejemplo son injustos precisamente porque no se ajustan a él? Por otra parte ¿no podemos suponer que una multitud de casos como los del ejemplo producen a la larga una injusticia estructural o sistémica que dicho principio no puede corregir, ni siquiera a través del principio de rectificación?

Como fuere, lo cierto es que cualquiera de las alternativas mencionadas a propósito del ejemplo podría alentar la convicción de que resulta conveniente añadir algún otro(s) (sub)principio(s) auxiliar a la teoría de Nozick para corregir las consecuencias que se siguen de la brecha entre el principio volenti non fit iniuria y las condiciones reales de contratación. En ese caso, la teoría del título válido (entitlement theory) de Nozick, podría oficiar como un ideal

\footnotetext{
${ }^{7}$ Por esa razón, al momento de resumir su propia teoría según la conocida máxima "de cada quien según su y a cada quien según su ", Nozick (1988, p.163)lo hace diciendo: "[...] de cada quien como escoja, a cada quien como es escogido". Por lo demás, la enunciación meramente formal que hace Nozick de los principios al comienzo del segundo capítulo deja más clara aún la correspondencia entre la teoría del título válido y el principio volenti non fit iniuria; (NOZICK, 1988, p. 154).

${ }^{8}$ Nos referimos al caso de aquellos actos que Aristóteles llama "mixtos" de voluntario con involuntario. Cf. Aristóteles (2002), E.N., Libro III, 1. Es interesante considerar las observaciones que a este respecto hace Vitoria (2006, p. 92): "[...] en las conmutaciones humanas no es suficiente para la justicia conmutativa el que por ambas partes sea algo absolutamente voluntario, sino que es necesario que no tenga mezclado algo de involuntario"; e inmediatamente ańade "[...] aquello que se hace por necesidad, aunque sea absolutamente voluntario, sin embargo tiene ańadido algo de involuntario”.
} 
regulativo más que como un conjunto de prescripciones a aplicar de modo directo e inmediato?.

No obstante, tal vez es injusto e incluso un poco improcedente someter una narración mítica a un examen como este. Evidentemente, Nozick ha preferido quedarse con la pureza del mito lockeano, recrearlo (y recrearse en él), para subrayar la justicia que subyace al principio volenti non fit iniuria: si todos los intercambios fueran voluntarios, entonces la distribución resultante sería por definición justa. Así las cosas, ¿por qué iba a ser necesario alguna otra regla adicional para juzgar y evaluar la corrección de una distribución determinada de bienes?

\section{LAS UTOPÍA LIBERTARIA}

La tercera parte de $A S U$ pretende ofrecer una línea argumental independiente en favor del Estado mínimo. Esa línea argumental es ofrecida bajo la forma de una utopía libertaria, esto es, una utopía cuyo único atractivo consiste en suponer un orden político en el que cada uno esté libre de impedimentos para escoger el modo de vida que prefiera. Ni más ni menos. La idea es, entonces, argumentar en favor del Estado mínimo por la vía de probar que éste es el único que ofrece las condiciones que harían posible la utopía libertaria. Por su parte, esta utopía descansa en una intuición moral fundamental que Nozick presenta e intenta defender no solo en $A S U$ sino también en algunas de sus obras posteriores ${ }^{10}$, a saber, que la vida solo puede tener sentido cuando se deja a cada persona vivir la suya del modo en que estime conveniente; que una persona sólo puede decir propiamente que su vida es suya cuando es ella quien decide cómo vivirla y no vive, por tanto, bajo las directrices, mandatos o prohibiciones de otra (NOZICK, 1988, p. 60 y ss.).

Esta intuición moral recoge los principios fundacionales del liberalismo clásico - antipaternalismo, tolerancia e individualismo - y permite a Nozick explotar el potencial utópico del mismo, de modo presentarlo como una doctrina atractiva e inspiradora. Con todo, dichos principios - que suelen traducirse en la regla que dice que cada uno puede vivir del modo que considere preferible en tanto con ello permita a los demás hacer lo propiopueden resultar demasiado escuetos como para alimentar una utopía de

\footnotetext{
${ }^{9} \mathrm{Al}$ respecto, cf. Nozick (1988, p. 282-283).

${ }^{10}$ Cf., por ejemplo, Nozick $(1981,1992)$.
} 
fuste ${ }^{11}$. Por eso, Nozick parece estar corriendo innecesariamente el riesgo de autoimponerse una tarea imposible de cumplir. A eso debe sumarse aún otra dificultad, más grave aún: el liberalismo parece estar esencialmente reńido con la formulación de proyectos utópicos. Si la utopía es forzosamente un relato construido sobre una cierta concepción particular de la vida buena, concepción que se proyecta a la organización social y política en su conjunto, al admitir una pluralidad de concepciones de la vida buena o, al menos, la imposibilidad de imponer de modo paternalista el modo de vida moralmente correcto, el liberalismo/libertarismo parece no solo estar conceptualmente impedido de ofrecer un proyecto utópico sino que además, como doctrina política, parece ser la negación misma no ya de la posibilidad sino incluso de la deseabilidad misma de las utopías ${ }^{12}$.

Nozick intenta resolver el primero de estos problemas del único modo en que es posible para una empresa tan ambiciosa como la suya: remite al lector la tarea de describir su propia utopía. Por tanto, si la utopía libertaria carece de enjundia es porque sus habitantes - que pueden escoger el tipo de vida que mejor les parezca - carecen de imaginación para pensar el curso de sus propias vidas y proyectos de modo que éstos resulten atractivos. El proyecto utópico libertario promete únicamente que, cualquiera que sea el proyecto personal que alguien tenga, éste podrá ser ensayado dentro de sus fronteras y bajo su amparo. La única condición que se impone a los distintos proyectos que se ensayen es la de reconocer la libertad equivalente de todos los demás para hacer lo propio. Las utopías que se intenten bajo su alero deben ser, por consiguiente, co-posibles. En este sentido, la estrategia de Nozick consiste en ofrecer simplemente las condiciones formales para toda utopía, en describir un marco que haga posible la coexistencia de todas las utopías particulares imaginables. Eso exige que la utopía libertaria deba ser considerada, como el mismo Nozick (1988, p. 300) advierte, no como una "utopía" sino como una "meta-utopía", esto es, como el lugar donde pueden tener lugar y expresarse todas las utopías y todos los proyectos utópicos. Así las cosas, la exclusión de los proyectos utópicos imperialistas no requiere de mayor

\footnotetext{
${ }^{11}$ Las utopías libertarias tienen más posibilidades cuando se las presenta literariamente como contrapunto de una distopía. Nozick, evidentemente, no tiene en ASU esa posibilidad a su alcance.

${ }^{12}$ Por ejemplo se pregunta retóricamente Kateb: “¿Debe el teórico utópico hacer honor a la doctrina del individualismo extremo y conceder que, después de la eliminación del mal radical y de la provisión de abundancia material, hay que dejar a la gente en paz, para ser y hacer más o menos lo que quiera?" (1982, p. 306). Aunque Kateb desecha rápidamente la pregunta, Nozick - y cualquier liberal con él — no dudaría en responder "[...] sí, eso es precisamente lo que hay que hacer".
} 
explicación ni justificación. Dicha exclusión es simplemente consecuencia de la incompatibilidad que existe entre los proyectos utópicos imperialistas y el principio que sirve de justificación al marco: que la vida de una persona solo puede tener sentido si puede vivirla del modo en que ella prefiera y decida (en adelante, y para abreviar, llamaremos a este principio "principio de la autonomía"); y puesto que es un reflejo de dicho principio, el marco solo es posible si se excluyen de antemano las utopías imperialistas; $y$ todas las razones que sirven para proscribir el derecho del más fuerte y el uso de la violencia como medio legítimo de imposición de un determinado programa político, aprovechan al marco libertario que proscribe las utopías imperialistas.

Como la formulación de la meta-utopía libertaria pone de manifiesto, el marco no es más que la aplicación del principio de la autonomía a la esfera jurídico-política y, por lo mismo, puede ser considerado como una especie de ley constitucional que otorga pleno reconocimiento y protección a la libertad civil $^{13}$. En ese sentido, como observa Lomasky, la utopía de Nozick, el marco meta-utópico, se alinea con (y, podemos añadir, puede ser vista como un desarrollo ulterior del) principio del daño de Mill (LOMASKY, 2002); podría decirse lo mismo con respecto al principio universal del derecho propuesto por Kant o, en fin, con respecto a la idea kantiana del gobierno patriótico que reconoce la plena libertad civil de sus miembros (KANT, AA, VIII, 290-291) ${ }^{14}$ : el marco libertario descrito por Nozick se alinea con dichos principios y los convierte en el eje de una (meta)utopía.

Pero, podríamos preguntarnos, ¿por qué una «meta-utopía» y no una "utopía» libertaria a secas? Nozick adelanta tres respuestas. La primera tiene que ver con la imposibilidad de definir de modo inequívoco el modo mejor de vida para todas las personas. Dadas las diferencias entre ellas, la idea, dice Nozick, de que existe una sociedad mejor para todos en la cual vivir es increíble:

\begin{abstract}
Wittgenstein, Elizabeth Taylor, Bertrand Russell, Thomas Merton, Yogi Berra, Allen Ginsburg, Harry Wolfson, Thoreau, Casey Stengel, The Lubavitcher Rebbe, Picasso, Moisés, Einstein, Hugh Heffner, Sócrates, Henry Ford, Lenny Bruce, Baba Ram Dass, Gandhi, sir Edmund Hillary, Raymond Lubitz, Buda, Frank Sinatra, Colón, Freud, Norman Mailer, Ayn Rand, el Barón de Rothschild, Ted Williams, Thomas Edison, H. L. Mencken, Thomas Jefferson, Ralph Ellison, Bobby Fischer, Emma Goldman, Piotr Kropotkin, usted y sus padres. ¿Existe realmente una sola
\end{abstract}

\footnotetext{
${ }^{13}$ Kukathas se extravía al analizar esta cuestión en (2011, p. 296 y ss.), pese a que por otra parte $A S U$ es una fuente obvia de inspiración de su obra de (2003).
}

${ }^{14}$ KANT, AA, VIII, 290-291. Cf. también AA, VI, 316 
clase de vida que sea mejor para cada una de estas personas? (NOZICK, 1988, p. 299).

Si no existe un único modo de vida que sea igualmente bueno para todos, entonces no existe una única utopía y ninguna visión utópica puede intentar llevarse a cabo de modo exclusivo sin transgredir el principio de la autonomía ${ }^{15}$.

La segunda respuesta puede ser considerada como una variación de la primera: puesto que no todos los bienes pueden ser realizados simultáneamente, habrá que recurrir a los trueques, y como no es verosímil suponer que un único sistema de intercambio satisfará a todos, será necesario ensayar diversos sistemas de trueque.

La tercera y última respuesta es ofrecida sobre el supuesto de que efectivamente existe un modo de vida objetivamente mejor para todos. Suponiendo que ese fuera el caso ¿cómo podría saberse cuál es ese modo de vida y la forma en que se lo debe implementar? Nozick ofrece una respuesta que pretende demostrar la conveniencia de adoptar el marco metautópico libertario: por la acción combinada de un mecanismo de diseńo y de un mecanismo de filtro, que equivalen a los diversos proyectos ideados y emprendidos por los diferentes habitantes y al marco legal definido por ideario libertario, respectivamente. En virtud del concurso de estos dos mecanismos, se fundarán diversas comunidades, con los más diversos proyectos, que crecerán, florecerán y desaparecerán alternativamente en virtud de las incorporaciones y deserciones de sus respectivos miembros. Este proceso continuo, posible y alentado por la libertad (renunciable) (NOZICK, 1988, p. 308 y ss) que el marco reconoce a los individuos, permite no solo diversos ensayos sociales, que pueden ser abandonados y eventualmente reintentados, sino que permite además la mejora continua de las comunidades que perduren, tanto a causa de la competencia entre ellas para ganar la adhesión de más miembros, como gracias a la experiencia acumulada a partir de los diversos experimentos. De este modo, la acción combinada de ambos mecanismos haría el descubrimiento del mejor modo de vida para todos (suponiendo que algo así exista) más fácil, dice Nozick (1988, p. 306), que cualquier otro mecanismo alternativo concebido para ese mismo fin.

\footnotetext{
${ }^{15}$ Con todo, uno podría preguntarse si acaso este principio acerca del sentido de la vida necesariamente lleva a la conclusión de la imposibilidad de una única utopía. Quizás bastaría con que, aun siendo cierto que existe un tipo de vida y de sociedad objetivamente mejor, en consideración al deber de dejar a los demás vivir su propia vida, éste no deba ser impuesto de modo paternalista.
} 
Para ilustrar el funcionamiento y las virtudes de un mecanismo de filtro, Nozick remite a la explicación de Hayek de los órdenes espontáneos (1988, p. 304 nota al pie). Al respecto, en la obra que Nozick cita, Hayek (2006, p. 63) afirma, entre otras cosas:

Todos los inventos de la civilización se ponen a prueba en la persecución de los objetivos humanos del momento: los inventos inefectivos serán rechazados y los efectivos mantenidos. Ahora bien, en ello hay algo más que el hecho de que los nuevos fines surgen constantemente con la satisfacción de viejas necesidades y con la aparición de nuevas oportunidades. La selección de individuos y grupos que lograrán el éxito y continuarán existiendo depende tanto de los fines que persigan y los valores que gobiernen sus acciones como de los instrumentos y actitudes de que dispongan. El que un grupo prospere o se extinga depende tanto del código ético al que obedece o de los ideales de belleza o bienestar que le guían como del grado en que ha aprendido o no a satisfacer sus necesidades materiales.

El modelo de Hayek supone que con el correr del tiempo ciertas formas de organización social serán seleccionadas - i.e., prevalecerán-y, en esa misma medida, la continua competencia entre ellas mejorará el producto final (i.e. la forma de sociedad resultante en cada estadio será más eficiente, satisfará más necesidades, etc.). Con todo, no debe llevarse la analogía entre el marco meta-utópico de Nozick y la explicación evolutiva de las instituciones de Hayek muy lejos. La analogía que interesa a Nozick es el modo en que opera el proceso de filtración, llamado también explicación de mano invisible funcional-evolutiva (ULLMANN-MARGALIT, 1978) ${ }^{16}$. La comparación de Nozick, en consecuencia, se limita a subrayar la función heurística que a largo plazo tiene un filtro como el descrito por Hayek, es decir, la función que posibilita que lleguemos a descubrir formas de organización que de otro modo no podríamos ni siquiera concebir. No obstante, el filtro es distinto en cada caso. En el caso de Hayek, el filtro es la capacidad adaptativa misma, mientras que en el de Nozick corresponde al marco legal libertario, por lo que la adaptación es el resultado de la adhesión y/o deserción voluntaria de los

\footnotetext{
${ }^{16}$ Cf. también NOZICK (1994) y (1988), p. 34: "Podemos mencionar aquí dos tipos de procesos de mano invisible por los cuales se puede producir una pauta P: procesos de filtración y procesos de equilibrio. Mediante el proceso de filtración únicamente pueden pasar cosas que satisfacen $\mathrm{P}$, porque los procesos o estructuras eliminan todos los no P. En el proceso de equilibrio cada parte componente responde o se ajusta a las condiciones "locales", cambiando con cada ajuste, el ambiente local de otros componentes cercanos, de tal forma que la suma de escarceos de los ajustes locales constituye o realiza P".
} 
miembros de las distintas comunidades. Como en el caso de Hayek, además, el orden emergente que resulta invariablemente favorecido en la selección - el que otorga una ventaja evolutiva - es un orden inintencionado que en parte nos resulta contraintuitivo ${ }^{17}$ y en parte nos resulta desconocido por lo que toca a las bases de su funcionamiento, bien puede ocurrir que los individuos sean incapaces de identificarse con el orden social emergente, que el producto del proceso evolutivo, aunque en muchos respectos les resulte ventajoso, les resulte chocante o indeseable en otros, con lo que el progreso podría ir indefectiblemente acompañado de un cierto grado de alienación. En la utopía de Nozick la adhesión voluntaria y los múltiples experimentos sociales vigentes y disponibles disminuyen, al menos ex hypothesi, el riesgo de que sucediera algo así (¿pero no es ya esta solución utópica en el sentido peyorativo del término? ¿No podría ocurrir, además, que experimentos socialistas de diversa índole se repitieran una y otra vez pese a todos sus fracasos? ¿O que las comunidades capitalistas fueran de modo más o menos inevitable colonizando otras de suerte que los proyectos de vida de estas últimas fueran haciéndose cada vez más imposibles de llevar a cabo y el propósito del marco, con ello, sobrepasado? ¿No deberíamos recordar a propósito de este eventual problema el primer capítulo del Manifiesto comunista?).

Otro modo de entender el funcionamiento del marco es compararlo con el funcionamiento del método de ensayo y error, y particularmente con la descripción que de dicho método ofrece Popper, pues es el mismo Nozick (1988, p. 304 nota al pie) el que remite a dicha descripción cuando habla del "[...] proceso de filtración del método científico". Más aún, posiblemente la comparación con la explicación de Popper es más iluminadora que la explicación a partir de la teoría evolutiva de Hayek.

Como se sabe, Popper cree que en estricto rigor no es posible justificar empíricamente teorías explicativas universales, sino que sólo es posible refutar las teorías científicas y, en esa medida, decidir si una teoría es preferible a otra sobre la base de las contrastaciones que cada una ha soportado o no. Y evidentemente una teoría no refutada es preferible a una que sí lo ha sido. De este modo, hay una competencia entre teorías rivales y aquella que es preferida a otra (por su mayor grado de corroboración) es no sólo más verdadera sino también más completa, en más de un sentido: explica mejor el fenómeno, pero además corrige la teoría rival y, en cierta forma, la abarca, en la medida

17 "El citado orden [extenso] es incluso «anti-natural» en el sentido más usual del término, es decir, en el de que no concuerda con la dotación biológica de la especie humana” (HAYEK, 2010, p. 50). 
en que ésta contenía al menos una aproximación al fenómeno que intentaba explicar (POPPER, 2010, p. 29-40). De este modo, aunque por razones simplemente lógicas no podamos llegar a establecer la verdad irrefutable de nuestro conocimiento, sí podemos desechar eventualmente mediante la contrastación las hipótesis y teorías falsas, acercándonos de este modo gradual e indefinidamente a la verdad. En consecuencia, aunque el método no garantiza la verdad, sí garantiza la posibilidad de librarnos del error. De igual modo, el filtro ofrecido por el marco meta-utópico no garantiza que de hecho se alcance la mejor de las sociedades imaginables. Al proponerlo, Nozick sencillamente está sugiriendo: a) que el marco es el medio más racional para probar distintos modos de vida y diferentes tipos de comunidades para así hallar o aproximarse lo más posible a la mejor de las sociedades imaginables; y que lo es además en un doble sentido: aumenta nuestras posibilidades de descubrimiento al tiempo que proscribe el uso de la violencia; b) gracias al marco se pueden ir mejorando progresivamente las diferentes modelos de comunidad; c) que el marco tiene además la ventaja de reintentar tentativas ya fracasadas o mejorar las exitosas variando partes de su estructura. En resumen, el marco constituye el mejor medio para explorar las distintas formas de organización social que podamos concebir sin necesidad de recurrir a la violencia. Esa sola posibilidad hace del libertarismo la mejor de las sociedades imaginables.

Llegado a este punto, y con el objeto de subrayar el principio moral que subyace al marco meta-utópico libertario, es tentador llevar la analogía más allá y extrapolar a la argumentación de Nozick una conclusión que el mismo Popper ofrece a propósito de su interpretación del método y del conocimiento científico. Popper sugiere - no una vez, sino constantemente - que la disposición del individuo racional puede quedar expresada en una actitud que no es teórica sino moral y que dice "[...] yo puedo estar equivocado y tú puedes tener razón y, con un esfuerzo, podemos acercarnos los dos a la verdad." (Popper, 2010, p. 438). Esta disposición, así como el principio que la expresa, supone la renuncia voluntaria al uso de la violencia y constituye, por lo mismo, la condición sine qua non de toda discusión racional. Como tal, no es susceptible de prueba ulterior (pues toda argumentación supone la adopción de la mentada máxima) y por ello puede afirmarse que la libre discusión de las ideas y teorías sobre las cuales funciona el método científico y que, en fin, el ejercicio mismo de la ciencia descansan en una disposición ética anterior a cualquier principio especulativo. Análogamente, y si es que es cierto que el marco refleja el principio de autonomía, entonces no es posible ofrecer pruebas puramente teóricas que resulten definitivas en su favor. En 
este sentido, el argumento teórico que a este respecto ofrece Nozick - que el marco es el único modo de descubrir el mejor modo de vida - debe ser visto como un argumento secundario que descansa, en último término, en el principio de autonomía, pues su aceptación depende de que se hayan abandonado las concepciones paternalistas de la política, del mismo modo que la praxis científica supone la disposición de someter a prueba las propias concepciones del mundo y, en definitiva, el abandono del fanatismo. Y si esta extrapolación del razonamiento de Popper a la utopía libertaria de Nozick es cierta, entonces el marco refleja también, a su modo, las únicas bases sobre las que es posible llevar a cabo una investigación y discusión racional acerca del modo idóneo de organizar la sociedad política; y si, en fin, ese es el caso ¿no podría el marco ser el objeto de elección por parte de agentes racionales y razonables que, ignorantes de sus circunstancias particulares, tuvieran que decidir acerca de los principios de convivencia y organización social? ${ }^{18}$

\section{CONCLUSIONES: LA PROPIEDAD SOBRE SÍ MISMO Y EL HILO CONDUCTOR DE $A S U$}

Nozick insiste en que $A S U$ ofrece dos líneas argumentales independientes en favor del Estado mínimo. Esa independencia ¡es tal que debemos entender que no hay vasos comunicantes entre esas dos líneas, que no hay un hilo conductor que vaya desde el mito del estado de naturaleza lockeano al mito de la utopía libertaria? ¿Es por tanto la convergencia entre ambas líneas, meramente accidental, al modo, por ejemplo, en que el consenso entrecruzado, tal como Rawls lo describe, sostiene la democracia liberal? Por consiguiente, y dependiendo de cómo se entienda este problema ¿habrá que decir que $A S U$ debe ser refutada dos veces para desestimar el Estado mínimo que en ella se defiende o que bastará con una sola contundente crítica dirigida al punto neurálgico que sirve de nexo entre los dos mitos?

No resulta aventurado afirmar que una misma intuición moral recorre todo el libro y que lo que hace Nozick no es más que tratar de explotarla de diferentes modos. Esta intuición, que es tematizada de modo parcial y tentativo al momento de tratar el fundamento de las restricciones morales indirectas, no es otra que la ya apuntada a propósito de la meta-utopía libertaria: cada persona debe poder vivir su vida por sí misma pues esa posibilidad constituye

\footnotetext{
${ }^{18}$ La meta-utopía de Nozick podría así ofrecer otra vía teórica al primer principio de la justicia de Rawls. Esta convergencia entre Nozick, Popper y Rawls acerca de la primacía de la libertad, por otra parte, no debiese causar extrañeza, puesto que todos se inscriben dentro de lo que, con alguna laxitud, puede denominarse la tradición "liberal".
} 
una condición necesaria (pero no suficiente) (NOZICK, 1988, p. 503) del sentido de la vida. El experimento mental de la máquina de experiencias, puede entenderse, está concebido, entre otras cosas, con el propósito de subrayar la importancia que dicho principio tiene en nuestra concepción intuitiva de aquello que resulta relevante y significativo para nuestra propia vida, para subrayar la alienación implicada en el hecho de no poder vivir nuestras propias vidas según una decisión consciente y deliberada. En consecuencia, se pregunta Nozick ¿por qué no conectarse a una máquina tal? Entre otras razones, responde, porque "[...] queremos hacer ciertas cosas, no sólo tener la experiencia de hacerlas"; porque, además, "[...] queremos ser de cierta forma, ser un cierto tipo de persona. Alguien que flota en un tanque es una burbuja indeterminada [...] Encadenarse a la máquina es una especie de suicidi (NOZICK, 1988, p. 54 , énfasis añadido)". Un poco más adelante recapitula su razonamiento para afirmar que lo más perturbador acerca de la máquina de experiencias (y de otras máquinas hipotéticas similares) es "[...] que vivan nuestras vidas por nosotros" (NOZICK, 1988, p. 55). Como todos esos pasajes sugieren, las diferentes negativas que pueden darse a la pregunta de si es o no apropiado enchufarse a una máquina como la descrita se reducen en definitiva a una sola: a que la vida carece de sentido si no podemos vivirla por nosotros mismos, y que vivirla por nosotros mismos significa ser alguien y llegarlo a ser por sí mismo ${ }^{19}$.

Pero suponiendo que el razonamiento de Nozick a este respecto es el correcto - y no es inverosímil afirmar que lo es- ¿cómo se conecta eso directa y explícitamente con la filosofía política y, en general el libertarismo expuesto y defendido en $A S U ?^{20}$

Para establecer esa vinculación es preciso atender primero a la concepción que Nozick tiene de la filosofía política y, más precisamente, del ámbito de competencia que atribuye a la filosofía política. A este respecto dice: "La filosofía política se ocupa únicamente de ciertas formas en que las personas no pueden usar a los demás; primordialmente: agresión física contra ellos." (NOZICK, 1988, p. 44) ${ }^{21}$.

\footnotetext{
${ }^{19}$ Cf. también NOZICK, 1981, p. 411-412.

${ }^{20}$ Pero, si la filosofía política, como el resto de la filosofía en general, tiene por finalidad conjurar el peligro de la alienación en sus diversas formas ¿por qué no reivindicar con el mismo fin alguna otra filosofía política, como por ejemplo el comunitarismo o el socialismo? El problema pasa por cuál de todas las teorías políticas conjura mejor dicho peligro y Nozick evidentemente cree que el libertarismo es precisamente esa teoría política. Llegados a este punto el razonamiento se vuelve circular o debe recurrir a argumentos dialécticos para demostrar la insuficiencia de las teorías políticas alternativas. El argumento de Wilt Chamberlain, por ejemplo, es un argumento de ese tipo.
}

${ }^{21}$ Cf. también NOZICK, 1981, p. 503; 2001, p. 281-282. 
Esta delimitación es, por supuesto, controvertida. Compáresela, por ejemplo, con la concepción que al respecto ofrece Aristóteles (III, 9, 1280b 5-12). Con todo, aquí la daremos por buena para, en cambio, preguntarnos entre la conexión entre esta definición y el principio de autonomía que recorre $A S U$. Consideremos algunas citas dispersas a lo largo de $A S U$ :

Una persona, voy a suponer, puede decidir hacerse a sí misma cosas que traspasarían los límites que rodean al espacio moral de su persona si fueran hechas por cualquier otra sin su consentimiento. (NOZICK, 1988, p. 66).

El consentimiento voluntario abre la frontera para cruzar [...] Locke sostendría que el que usted dé su consentimiento no hace moralmente permisible que otro lo mate, porque usted no tiene derecho de suicidarse. Mi posición no paternalista sostiene que alguno puede decidir (o permitir a otro) hacerse a sí mismo $\cos a$, salvo que haya adquirido la obligación ante cualquier tercero de no hacerlo o no permitirlo. (NOZICK, 1988, p. 67).

Este proceso [por el cual otros le imponen a Ud. la obligación de realizar un determinado de trabajo o de pagar un impuesto]... los hace co-propietarios de usted; les otorga un derecho de propiedad sobre usted. (NOZICK, 1988, p. 174).

Estas tres citas están tomadas de las dos primeras parte de $A S U$; la última de ellas está tomada de aquella en que Nozick argumenta en contra de la licitud del Estado más que mínimo. La siguiente está tomada de la tercera parte: "La pregunta comparable sobre un individuo es si un sistema libre le permitiría venderse a sí mismo como esclavo. Creo que sí.” (NOZICK, 1988, p. 317).

Considerando estas citas, y pese a que Nozick nunca lo menciona explícitamente, no es difícil descubrir el hilo conductor que recorre $A S U$ : la propiedad sobre si mismo ${ }^{22}$, esto es, la idea de que cada uno debe gozar de la libertad para poder hacer de sí lo que quiera mientras con ello no dañe a otros (i.e., la propiedad que otros tienen sobre sí mismos). Este "hacer de sî", por tanto, y como queda claro por las citas, no está sujeto a ningún tipo de restricción paternalista o perfeccionista. En este sentido, puede entenderse que Nozick está reinterpretando la noción de propiedad sobre sí mismo de Locke de modo que pueda ser formulada como el principio general de una teoría jurídica y política liberal cuya enunciación podría rezar: "son conformes a derecho/son legítimas aquellas acciones que respetan el derecho de propiedad que los otros tienen sobre sus propias personas". La propiedad sobre sí mismo

${ }^{22}$ El mérito de este descubrimiento es de Cohen (1995). 
será, entonces, la traducción al ámbito jurídico-político de lo que aquí hemos llamado el "principio de autonomía".

Aunque el concepto de propiedad sobre sí mismo permite vincular eficazmente los dos mitos que constituyen la obra, uno podría preguntarse aún cuál de ellos expresa mejor el principio de autonomía que le sirve de inspiración general. Y no parece inverosímil afirmar que es la meta-utopía libertaria, con todas sus posibles ramificaciones, manifestaciones y aplicaciones, la que mejor lo hace. Por paradójico que resulte, la posibilidad de crear comunidades y micro-utopías paternalistas y antilibertarias es precisamente la prueba de ello. $Y$ si ese es el caso, bien podría haber ocurrido que los adversarios del mito libertario, distraídos en el combate contra las dos primeras partes de $A S U$, hayan dejado prácticamente en paz e intactas las cabezas más importantes de la Hidra creada por Nozick.

AUGIER, Felipe Schwember. Contract and utopia: the continuity and discontinuity of the libertarian myths of anarchy, state, and utopia. Trans/form/ação, Marília, v. 39, n. 4, p.127-152, Out./Dez., 2016.

\begin{abstract}
This paper examines Robert Nozick's Anarchy, State, and Utopia in the light of the myths and fictions upon which it is built. I hold that it is possible to identify two main myths: the Lockean state of nature, whose principle can be summarized by the maxim volenti non fit injuria, and the libertarian meta-utopia, that can be explained as an application of Hayek evolutive theory and of Popper's epistemology in order to construct an utopia. I also claim that there is a continuity between both myths, and that this continuity is granted by a moral intuition that Nozick presents at the beginning of this work, and that also inspires the libertarian myth: that life can only have sense when each person is allowed to live her own in the way she deems convenient. I will conclude that this intuition finds an expression, in the field of politics and law, in the principle that each person owns herself and, hence, that this peculiar form of ownership is the secret thread of the whole book.
\end{abstract}

KEYWORDS: Lockean contractualism. Nozick. Natural law. Utopia. 


\section{REFERÊNCIAS}

ARISTÓTELES. Ética a Nicómaco. Traducido por María Araujo y Julián Marías. Madrid: Centro de Estudios Políticos y Constitucionales, 2002.

. Política. Traducido por Julián Marías y María Araujo. Madrid: Centro de Estudios Políticos y Constitucionales, 2005.

COHEN, G. A. Self-ownership, Freedom and equality. New York: Cambridge University Press, 1995.

FRYE, N. Diversidad de utopías literarias. In: MANUEL, Frank E. (Ed.). Utopias y Pensamiento Utópic. Traducido por Magda Mora. Madrid: Espasa-Calpe, 1982. p. 55-81.

HAYEK, F. Los fundamentos de la libertad. Traducido por José Vicente Torrente. Madrid: Unión Editorial, 2006.

KANT, I. Kants Gesammelte Schriften herausgegeben von der Königlich Preussischen Akademie der Wissenschaften. V. I-XXVIII. Berlin, Leipzig: Georg Reimer; Walter de Gruyter, 19101917;1923-1972.

KATEB, G. La utopía y la vida buena. In: FRANK, E. M. (Ed.). Utopias y pensamiento utópico. Traducido por Magda Mora. Madrid: Espasa-Calpe, 1982. p. 289-311.

KUKATHAS, C. The liberal archipielago: a theory of diversity and Freedom. New York: Oxford University Press, 2003.

E pluribus plurum, or How to fail to get to utopia in spite of really trying. In: BAADER, R. M.; MEADOWCROFT, J. (Ed.). The Cambridge Companion to Nozick's anarchy, state, and utopia. New York: Cambridge University Press, 2011. p. 289-302.

LOCKE, J. Two treatises of government. 3.ed. Editado por Peter Laslett. New York: Cambridge University Press, 1988.

LOMASKY, L. E. Nozick's libertarian utopia. In: SHMIDTZ, D. (Ed.). Robert Nozick. New York: Cambridge University Press, 2002. p. 59-82.

MACK, E. Nozick on unproductivity: the unintended consequences. In: PAUL, J. (Ed.). Reading Nozick: essays on anarchy, state and utopia. Oxford: Basil Blackwell, 1982. p. 169-190.

. Nozickian arguments for the more-than-minimal. In: BAADER, R. M.; MEADOWCROFT, J. (Ed.). The Cambridge Companion to Nozick's Anarchy, State, and Utopia. New York: Cambridge University Press, 2011. p. 89-115.

NOZICK, R. Anarchy, state, and utopia. Oxford: Basic Books, 1974.

. Philosophical explanations. Cambridge: Harvard University Press, 1981.

. Anarquía, estado y utopía. Traducido por Rolando Tamayo. México: Fondo de Cultura Económica, 1988. 
. Meditaciones sobre la vida. Traducido por Carlos Gardini. Barcelona: Gedisa, 1992. Invisible-hand explanations. The American Economic Review, v. 84, n. 2, p. 314318, mayo 1994.

- La naturaleza de la racionalidad. Traducido por Antoni Domènech. Barcelona: Paidos, 1995.

. Invariances. Cambridge: Harvard University Press, 2001.

POPPER, K. R. La sociedad abierta y sus enemigos. Traducido por Eduardo Loedel y Amparo Gómez Rodríguez. Barcelona: Paidós, 2010.

ULLMANN-MARGALIT, E. Invisible hand explanations. Synthese, n. 39, p. 263-291, 1978.

VITORIA, F. Contratos y usura. Traducido por María Idoya Zorroza. Pamplona: EUNSA, 2006.

Recebido em 10/02/2016

Aceito em 07/05/2016 